\title{
Patients with Cluster A Personality Disorders in Psychotherapy: An Effectiveness Study
}

\author{
Anna Bartak $^{\mathrm{a}, \mathrm{c}}$ Helene Andrea ${ }^{\mathrm{c}, \mathrm{e}}$ Marieke D. Spreeuwenberg ${ }^{\mathrm{f}, \mathrm{g}}$ \\ Moniek Thunnissen $^{h}$ Uli M. Ziegler ${ }^{i}$ Jack Dekker $^{b} \quad$ Fleur Bouvy $^{j}$ \\ Elisabeth F.M. Hamers ${ }^{d}$ Anke M.M.A. Meermank Jan J.V. Busschbach ${ }^{\text {c, e }}$ \\ Roel Verheul $^{\mathrm{a}, \mathrm{d}}$ Theo Stijnen' Paul M.G. Emmelkamp ${ }^{\mathrm{a}}$ \\ a Department of Clinical Psychology, University of Amsterdam, and ${ }^{\mathrm{b}}$ Arkin, Amsterdam, ${ }^{\mathrm{C}}$ Institute for Studies on \\ Personality Disorders (VISPD) and ${ }^{\mathrm{d}}$ Psychotherapeutic Centre De Viersprong, Halsteren, ${ }^{e}$ Department of Medical \\ Psychology and Psychotherapy, Erasmus Medical Centre, Rotterdam, ${ }^{\mathrm{f}} \mathrm{Hogeschool} \mathrm{Zuyd,} \mathrm{Heerlen,}{ }^{9}$ Department \\ of Methodology and Statistics, Tilburg University, Tilburg, hGGZWNB, Bergen op Zoom, 'Zaans Medical Centre, \\ Zaandam, ${ }^{j}$ Altrecht, Zeist, ${ }^{k}$ De Gelderse Roos, Lunteren, and 'Department of Medical Statistics and Bioinformatics, \\ Leiden University Medical Centre, Leiden, The Netherlands
}

\section{Key Words}

Personality disorders $\cdot$ Psychotherapy $\cdot$ Treatment effectiveness $\cdot$ Treatment outcome $\cdot$ Schizoid personality disorder $\cdot$ Paranoid personality disorder $\cdot$ Schizotypal personality disorder

\footnotetext{
Abstract

Background: While psychopharmacological studies are common in patients with cluster A personality disorders, the effects of psychotherapy have received little attention. The aim of this study is to explore whether psychotherapeutic treatment yields health gains for these patients. Methods: The study was conducted between March 2003 and June 2008 in 6 mental health care centres in the Netherlands, with a sample of 57 patients with a DSM-IV-TR axis II cluster A diagnosis. Patients were assigned to 3 settings of psychotherapeutic treatment (outpatient, day hospital, inpatient), and effectiveness was assessed at 18 months after baseline. An intention-to-treat analysis was conducted for psychiatric
}

symptoms (Brief Symptom Inventory), psychosocial functioning (Outcome Questionnaire-45) and quality of life (EQ5D), using multilevel statistical modelling. As the study was non-randomised, the propensity score method was used to control for initial differences. Results: Patients in the day hospital and inpatient group improved substantially in terms of psychiatric symptoms, social and interpersonal functioning, and quality of life. Patients in the outpatient group showed less improvement. Direct comparison of the improvement of psychiatric symptoms showed significant results in favour of day hospital $(p=0.046)$ and inpatient $(p=$ 0.01) treatment, as compared to outpatient treatment. However, due to substantial baseline differences, this direct comparison should be judged carefully. Conclusions: Cluster A psychopathology is not a contraindication to benefit from psychotherapy. This is especially true for more intensive forms like inpatient and day hospital treatment. Future research should focus more on psychotherapeutic treatment to gain further insight into effective treatment options for this patient group.

Copyright $\odot 2010$ S. Karger AG, Basel

\section{KARGER}

Fax +41613061234 E-Mail karger@karger.ch www.karger.com
(C) 2010 S. Karger AG, Basel

0033-3190/11/0802-0088\$38.00/0

Accessible online at:

www.karger.com/pps
Anna Bartak

Department of Clinical Psychology

University of Amsterdam, Roetersstraat 15

NL-1018 WB Amsterdam (The Netherlands)

Tel. +31 62822 7811, Fax +31 20639 1369, E-Mail a.bartak@uva.nl 


\section{Introduction}

Paranoid, schizoid and schizotypal personality disorders (PD) are associated with significant psychological and functional impairment and a poor long-time prognosis [1-6]. Estimates for their prevalence in the general population range from 1.6 to $4.1 \%$ [7-9]; in psychiatric outpatients they are even more common (5.6-13.2\% [1, 10]). Therefore, it is important to investigate which treatment forms can produce significant and long-lasting improvement in the life of these patients.

Psychotherapy is recommended as the treatment of choice for patients with PD in general [11]. More specifically, clinical experts suggest psychotherapy as the first treatment option for cluster A PD patients [12-14]. Yet, psychotherapy effectiveness studies on the 'odd' cluster A $\mathrm{PD}$ are rare. Most existing studies investigate the impact of cluster A PD on treatment effects of axis I treatments or focus on the effectiveness of psychopharmacological treatment of schizotypal PD. It has been shown in these studies that the presence of cluster A PD, especially schizotypal PD, has a negative influence on the outcome of axis I treatments of both medical and psychotherapeutic kind [15-19]. Medication studies of schizotypal PD have shown that typical and atypical antipsychotics, and possibly antidepressants, can have a positive influence on distinguished symptoms, such as cognitive disturbance, derealisation, ideas of reference, anxiety, self-image, social and overall functioning, odd communication, obsessive-compulsive symptoms and self-injury [20-29]. The influence of medication on depressive symptoms in schizotypal patients is still controversial [20, 22, 24, 25]. There is no 'agent of choice' [30], and medication side effects are common, especially in typical neuroleptics [21]. Moreover, it is repeatedly stated that whatever the value of pharmacological treatment may be, the quality of the therapeutic relationship is one of the most crucial aspects in the treatment of cluster A PD patients [26].

Possible reasons for the paucity of research in this patient group might be the fact that cluster A PD patients seldom seek help from the psychiatric profession and the lack of consensus among clinicians about the effectiveness of psychotherapy in this patient population $[14,31]$.

This lack of consensus is maintained because the few effectiveness studies of psychotherapy in cluster A PD patients show contradicting results. Plakun et al. [32] studied former inpatients at the 'Austin Riggs Center' of whom 43 had a cluster A PD. They were classified into 4 groups: (1) pure schizotypal PD patients $(\mathrm{n}=13),(2)$ combined borderline and schizotypal PD patients $(n=6),(3)$ com- bined borderline with schizoid PD patients $(\mathrm{n}=5)$, and (4) pure schizoid PD patients $(n=19)$. They found the highest improvement of general functioning in the combined borderline and schizotypal PD group. After a follow-up period of 14 years, this group functioned significantly better than the comparison group of schizophrenic patients, with a Global Assessment Scale score [33] of 72.0. The other 3 cluster A PD groups also improved in their Global Assessment Scale score, but still functioned at a level comparable to schizophrenic patients at followup, with mean Global Assessment Scale scores between 55.6 and 66.6.

In their studies on day hospital treatment, a Norwegian research group found poor results regarding psychiatric symptoms and psychosocial functioning for patients with schizotypal PD ( $n=9$, with or without comorbid borderline PD) $[34,35]$. Their study sample also included patients with paranoid PD $(n=4)$ and schizoid PD $(n=5)$, but their results were not reported separately. The same holds true for the small group of cluster A PD patients $(n=4)$ in a study of Winston et al. [36]. On the other hand, Gude and Vaglum [37] in their study on inpatients found no differences in improvement of psychiatric symptoms and occupational status between pure cluster A PD patients $(n=21)$ and both pure cluster $B$ and pure cluster $C$ patients. However, their sample of cluster A PD patients included only few patients with schizotypal PD.

The largest study reporting on cluster A PD patients is the study on day hospital treatment conducted by Karterud et al. [38]. Their sample contained 132 cluster A PD patients (treatment completers; $\mathrm{n}=16$ for schizotypal PD as 'main' diagnosis, $\mathrm{n}=8$ for schizoid $\mathrm{PD}$ and $\mathrm{n}=108$ for paranoid PD), including cluster A PD patients with comorbid cluster B and/or C PD. Their findings indicated that patients with cluster A PD had a high dropout rate in day hospital treatment (23.9\%) and that patients with paranoid and schizotypal PD showed only modest treatment gains regarding psychiatric symptoms, quality of life and overall functioning. Patients with paranoid PD and comorbid borderline PD had significantly worse results at the 1-year follow-up than patients with borderline $\mathrm{PD}$ alone. As the group of patients with schizoid PD was too small, their follow-up results were not reported.

Given that psychotherapy studies in cluster A PD patients are scarce and the evidence is conflicting, it is important to investigate further if psychotherapy can bring about change for these vulnerable patients. There are substantial differences between treatment options in terms of time and money. That makes it relevant for both pa- 
tients and society to know which setting of psychotherapy (outpatient, day hospital or inpatient treatment) is sufficiently efficient to produce positive change. Yet, no study has compared the outcomes of different treatment settings for patients with cluster A PD.

The aim of the present study is to explore the effects of psychotherapy on patients with cluster A PD. More specifically, we want to answer the following research questions: (1) What is the change in psychiatric symptoms, social and interpersonal functioning, and quality of life in patients with cluster A PD 18 months after baseline? (2) What is the effect of different treatment settings, i.e. outpatient, day hospital and inpatient treatment?

\section{Methods}

In this study we used a prospective naturalistic study design. To correct for the influence of selection bias due to non-randomisation, we used the propensity score method (see below). For details of the method section, we refer to our earlier studies on cluster $\mathrm{C}$ and B PD patients $[39,40]$.

\section{Participants}

Participants $(n=57)$ were recruited from consecutive admissions to 6 mental health care centres in the Netherlands. The institutions offer outpatient, day hospital and/or inpatient psychotherapeutic treatment for patients with personality pathology. From March 2003 to March 2006, 1,379 patients completed the intake and screening procedure and were selected for treatment (fig. 1). The intake and screening data were collected for all applicants, irrespective of study participation later on. The data obtained from this initial assessment served as baseline data for our study. As it was part of the standard screening procedure, informed consent for the baseline data collection was not mandatory under Dutch law.

Of these 1,379 patients, 146 (10.6\%) were excluded from the study for not meeting one of the following inclusion criteria: age between 18 and 70 years $(n=13)$, significant personality pathology $(n=34)$ and referral for psychotherapeutic treatment aimed at personality problems $(n=99)$. Nine patients $(0.7 \%)$ met one of the following exclusion criteria: insufficient command of the Dutch language $(n=6)$, organic cerebral impairment $(n=1)$, mental retardation $(n=1)$ and schizophrenia $(n=1)$. This left 1,224 participants, of whom 31 (2.5\%) could not participate due to logistic reasons. A total of 133 patients (10.9\%) had to be excluded due to missing or unreliable baseline data during the intake and screening procedure. For the majority of these 133 patients $(\mathrm{n}=$ 106), no standardised axis II diagnosis was obtained. This was mostly due to a practical problem, i.e. a shortage of interviewers at the start of the study $(\mathrm{n}=101)$. Because of this logistic reason, it can be assumed that these data were 'missing completely at random' and therefore they do not threaten internal validity (as they were unrelated to specific patient characteristics). Five patients had an unreliable axis II diagnosis as determined by the interviewer. A few patients did not return their assessment booklet during the intake procedure $(\mathrm{n}=27)$. Thirty-eight patients $(3.1 \%)$ received less than 2 treatment sessions of outpatient therapy or less than 2 days of inpatient or day hospital therapy. They were therefore excluded beforehand from the study sample in which we only included patients with a 'minimal effective dose' of treatment. One hundred patients (8.2\%) refused to participate. The remaining 922 patients were informed about the study and its procedure, provided written informed consent and entered the study. Of those, 71 patients (7.7\%) had 1 or more cluster A PD.

In the absence of explicit guidelines for treatment assignment in PD [41], the treatment selection procedure was based on the expert opinion of clinicians who used their clinical experience combined with patient data from standardised instruments. To clarify the criteria used for the assignment process, our research group had recently conducted a study with intake clinicians from the participating treatment centres. We found evidence of substantial consensus among clinicians concerning the criteria used for treatment decision making. Variables guiding the treatment selection process include the focality of problems, ego strength, symptom severity, psychological mindedness, relational capacities and quality of defence mechanisms [42].

The 71 cluster A PD patients were assigned to 1 of 3 setting groups, based on the regular treatment assignment done by expert clinicians at the clinical sites: 24 patients to outpatient, 27 patients to day hospital and 20 patients to inpatient treatment. Follow-up data were not available for 14 patients (19.7\%). There was no difference in psychiatric symptoms at baseline between patients with follow-up data and those without. The final sample consisted of 57 patients who were included in the analyses.

\section{Treatment}

The 6 mental health care centres offer a variety of psychotherapeutic treatments tailored to a PD patient population. Their treatments differ according to several features. As this study focused on different treatment settings, the following 3 treatment groups were compared: (1) Patients in outpatient treatment $(\mathrm{n}=$ $20,35.1 \%$ of the study sample). These patients came for individual $(75.0 \%)$ or group (25.0\%) psychotherapy sessions for up to 2 sessions/week (mean 1.0 session/week, SD 0.6, median 0.9; mean treatment duration 13.3 months, SD 6.2, median 12.0). Four health care centres offered outpatient treatment. (2) Patients in day hospital treatment $(n=19,33.3 \%$ of the study sample). These patients came at least 1 morning/afternoon per week (mean 3.3 days/week, SD 1.6, median 3.0) and received different forms of psychotherapeutic and psychosocial treatment, but slept at home (mean treatment duration 10.3 months, SD 4.5, median 9.0). Five health care centres offered day hospital treatment. (3) Patients in inpatient treatment $(\mathrm{n}=18,31.6 \%$ of the study sample). These patients stayed at the institutions 5 days a week and received different forms of psychotherapeutic and psychosocial treatment (mean treatment duration 8.6 months, SD 2.4, median 8.5). Three health care centres offered inpatient treatment.

Outpatient treatments consisted of individual or group psychotherapy sessions of various theoretical orientations $(50 \%$ eclectic, 20\% psychodynamic, 20\% cognitive-behavioural, $10 \%$ other). Day hospital and inpatient programmes typically consisted of group psychotherapy as a core element, mostly in combination with 1 or more non-verbal or expressive group therapies, individual psychotherapy, sociotherapy within the therapeutic community, coaching for social problems, community meetings and/or pharmacological treatment. The therapists were all li- 
Fig. 1. Patient flow. ${ }^{1}$ These patients did not receive a 'minimal effective dose' of treatment, defined as 2 sessions for outpatients and 2 treatment days for day hospital patients or inpatients, and were therefore not included in the initial study sample.

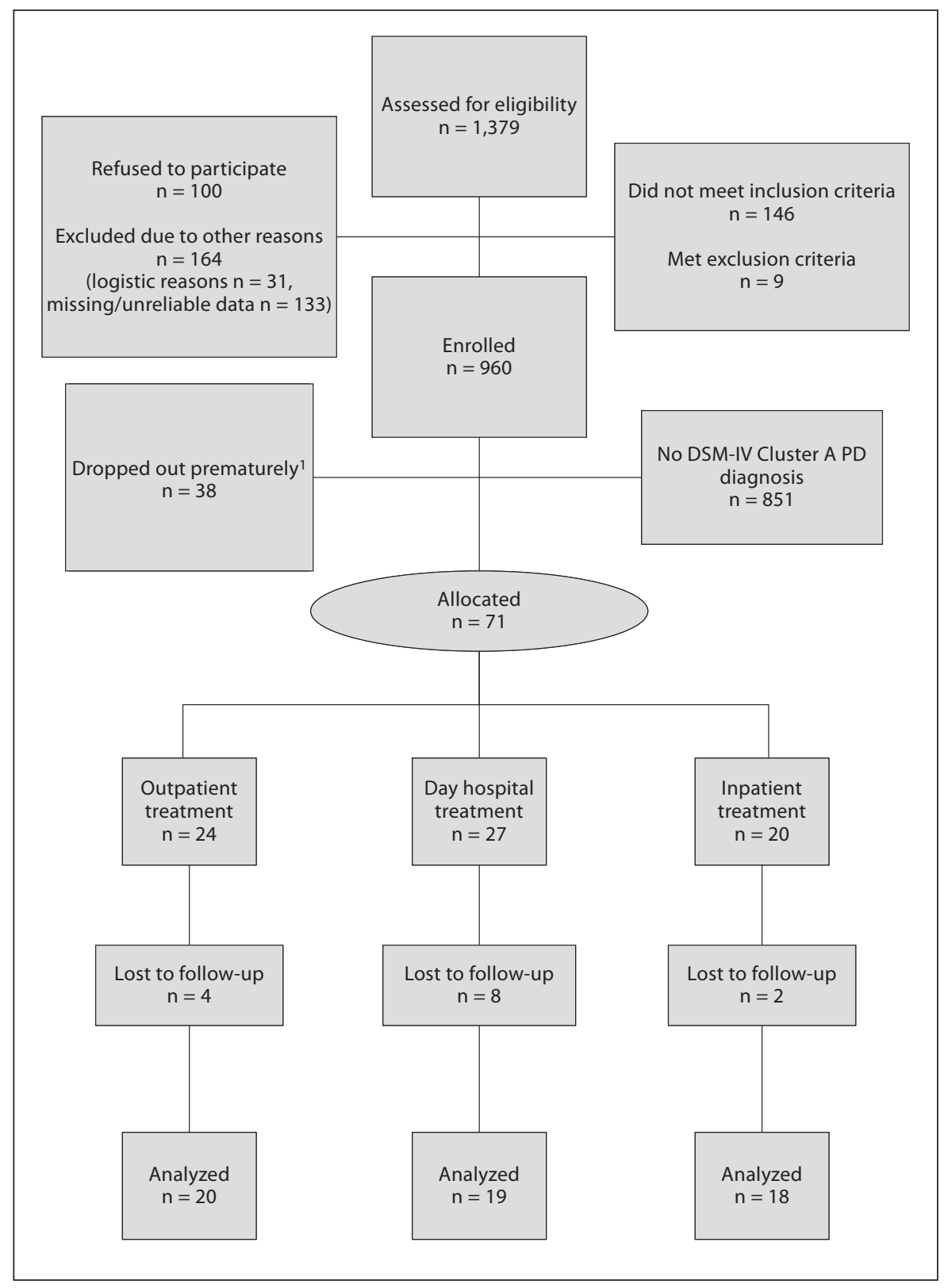

censed psychiatrists or psychologists. On average, they had 14.9 years $(\mathrm{SD}=10.1$ ) of postgraduate clinical experience. The treatments under study can be considered highly representative of regular clinical practice in the Netherlands, as therapists did not receive specific training for this study and treatment integrity was not monitored. The study protocol was approved by the Medical Ethics Committee of the Erasmus University Medical Centre in Rotterdam.

\section{Assessments}

Baseline Measures. An extensive standard assessment battery of instruments was administered to the patients before treatment assignment. PD were measured using the Dutch version of the
Structured Interview for DSM-IV Personality [43, 44]. To measure patient characteristics at baseline, the assessment battery also included 3 self-report instruments. The first of those was the Dutch version of the Dimensional Assessment of Personality Pathology Basic Questionnaire, for measuring type and degree of personality pathology $[45,46]$. We used patient scores on this questionnaire on the 4 higher-order factors: emotional dysregulation, dissocial behaviour, inhibition and compulsivity. To measure the severity of personality pathology, we used the 5 higherorder domains of the Severity Indices of Personality Problems, Dutch version: self-control, social concordance, identity integration, relational capacities and responsibility [47]. To measure the patients' motivation for treatment, we used the 2 scales of the Mo- 
Table 1. Variables used for propensity score estimation, outcome GSI

\begin{tabular}{ll}
\hline Variable & Content \\
\hline DAPP-BQ Emotional dysregulation & Unstable affective responding, interpersonal problems \\
DAPP-BQ Compulsivity & Compulsivity and absence of oppositional behaviour \\
MTQ-8 Need for help & Patient's expressed desire for external help \\
SIPP Self-control & Capacity to tolerate, use and control one's own emotions and impulses \\
OQ-45 Symptom distress & Level of symptom distress \\
OQ-45 Relational functioning & Level of interpersonal functioning \\
SIDP-IV Cluster B PD & Number of cluster B PD \\
SIDP-IV Cluster C PD & Number of cluster C PD \\
SIDP-IV Dimensional score cluster B PD & Dimensional score of cluster B PD characteristics \\
SIDP-IV Dimensional score cluster C PD & Dimensional score of cluster C PD characteristics \\
SIDP-IV Total dimensional score & Total dimensional score of PD characteristics \\
Drug abuse & History of drug abuse \\
Borderline PD & Diagnosis of borderline PD \\
Narcissistic PD & Diagnosis of narcissistic PD \\
\hline
\end{tabular}

DAPP-BQ = Dimensional Assessment of Personality Pathology - Basic Questionnaire; MTQ-8 = Motivation for Treatment Questionnaire; SIPP = Severity Indices of Personality Problems; OQ-45 = Outcome Questionnaire-45; SIDP-IV = Structured Interview for DSM-IV Personality.

tivation for Treatment Questionnaire: need for help and readiness to change [48].

Outcome Measures. The primary outcome measure was general psychiatric symptomatology. This was measured using the Dutch version of the Brief Symptom Inventory [49, 50], a validated self-report scale derived from the Revised Symptom Checklist $90[51,52]$. In this study, we used the mean score of the 53 items of the Brief Symptom Inventory, i.e. the Global Severity Index (GSI), ranging from 0 to 4 , with higher scores indicating more problems. Psychosocial functioning was measured with 2 subscales of the 45-item Outcome Questionnaire (OQ-45), Dutch version: (1) interpersonal relations and (2) social role functioning [53]. The total scores of these 2 scales range between 0 and 44, and between 0 and 36, respectively, with higher scores indicating more problems. Health-related quality of life was measured using 2 scales of the Dutch version of the EuroQol questionnaire EQ-5D [54], with higher scores indicating a higher quality of life: the EQ$5 \mathrm{D}$ index, which represents the societal value (i.e. the valuation of a particular health state as rated by the society) of quality of life with a value between 0 and 1 , and the EQ visual analogue scale (EQ-VAS) which represents the patient's own value of quality of life on a scale from 0 to 100 . All 5 outcome measures, GSI, OQ-45 social role, OQ-45 interpersonal relations, EQ-5D index and EQVAS, were assessed at baseline and several follow-up moments. Three of the 6 treatment centres conducted their follow-up measurements at 12,24 and 36 months after baseline; the other 3 treatment centres conducted their follow-up measurements at the end of treatment, subsequently 6 and 12 months after that, and again at 36 months after baseline. The use of different assessment points was due to logistic reasons in the participating centres. As some follow-up points were related to the end of treatment and treatment duration varied considerably, we had no common measurement point for all patients to determine mid-term outcome. This was taken into account by choosing multilevel modelling as the statistical method for the analyses. Multilevel modelling enabled us to make use of all the available data collected for every patient at multiple assessment points between baseline and 36 months and to reliably estimate change at 18 months.

\section{Statistical Analyses}

We first examined the uncorrected results on all 5 outcome measures estimated at 18 months after baseline, thus without applying the propensity score method. We used multilevel modelling to deal with (1) the dependency of repeated measures on the same subject in time and (2) longitudinal data with observations unequally spaced in time (see 'Outcome Measures'). To estimate the uncorrected treatment effect at 18 months after baseline, we used a random intercept and random slope model with time as level I and patient number as level II. This resulted in a model with the following independent variables: dummy variables indicating treatment group membership, time, and interaction between group membership and time. In these analyses, we used all available follow-up data from baseline to 36 months, but since we focused on mid-term outcome, we used the estimated change scores at 18 months after baseline, based on the results of the model. Subsequently, we calculated within-group effect sizes (Cohen's d) [55] to describe change from baseline to 18 months per treatment group (outpatient, day hospital, inpatient).

However, treatment groups cannot be compared directly based on the uncorrected results in this non-randomised clinical trial as these findings might be confounded by initial patient differences. To adjust for these differences and to avoid bias in effect estimation, we used the propensity score method. The classic propensity score is defined as the conditional probability of assignment to 1 of 2 treatment groups given a set of observed pretreatment variables [56]. Propensity scores are used to reduce selection bias by equating groups based on these variables. Since we had to compare 3 treatment groups, we included a 'multiple propensity 
score' in our analysis. The multiple propensity score is an extension of the classic propensity score to more than 2 treatment groups [57]. To identify relevant confounders, we considered a long list of social, economic and diagnostic variables carefully selected by both clinicians and researchers, based on the literature and clinical knowledge [58]. All variables significantly related to a specific outcome were used to estimate the multiple propensity scores in a multinomial regression analysis, with group membership as a dependent variable (for the variables included in the GSI propensity score, see table 1; complete list of potential/identified confounders for all outcome variables available upon request). A major advantage of the propensity score method, as compared to other correction techniques, is the fact that the overlap in propensity score distributions (and thus the overlap in relevant variables) between treatment groups can be easily judged and visualised [59]. If the distribution of propensity scores shows large overlap in the different treatment groups, the groups are readily comparable. If, however, overlap is insufficient, groups differ too much and their direct comparison might yield results which cannot unequivocally be attributed to a treatment effect. For a detailed description of the propensity score method and its use in psychotherapy research, see Bartak et al. [58] and Spreeuwenberg et al. [59].

To compare change in outcome variables across treatment groups adjusted for baseline patient characteristics, a more sophisticated multilevel model, now including multiple propensity scores, was used. Dependent variables were all available change scores observed during follow-up for each of the outcome measures. The following independent variables were entered in the initial model: dummy variables indicating group membership, time, the multiple propensity scores and their interactions. Then independent variables were eliminated from the model by backward selection to obtain a final best-fit model. This model estimated differences in change scores at 18 months after baseline in pair-wise comparisons of the 3 treatment groups.

Follow-up response was high, enhancing the robustness of the estimations at 18 months: $77.2 \%$ of the patients had 3 or more follow-up measurements between baseline and 36 months. The analyses were performed using SPSS 17.0 for data preparation and Proc Mixed of SAS 9.1.3 for multilevel modelling (SAS Institute Inc., Cary, N.C., USA).

\section{Results}

\section{Sample Characteristics}

Of the 57 patients, $70.2 \%$ were female (table 2). The mean age was 29.4 years $(\mathrm{SD}=8.2)$, and $78.9 \%$ were unmarried. The level of education was low for $43.9 \%$, medium for $10.5 \%$ and high for $45.6 \%$. The majority $(86.0 \%)$ had a diagnosis of paranoid PD. Only a minority (15.8\%) had pure cluster A PD, while the remaining patients had cluster A PD and comorbid cluster B and/or C PD.

As can be seen in table 2, patients in the 3 treatment groups differed substantially on a number of baseline variables. Significant differences appeared in age, marital status, baseline severity of psychiatric symptoms and baseline severity of quality of life. These substantial differences complicate the adjustment of the results with the propensity score. Indeed, the overlap in the distribution of propensity scores was imperfect (fig. 2), and the results of these 3 groups of patients were not readily comparable, even after applying propensity score correction. One has to keep that in mind when judging possible group differences in change scores.

\section{Treatment Compliance}

Before start of treatment, every patient received an allocation to a certain 'treatment dosage' in terms of setting and duration. According to our registration at the end of treatment, about one quarter of all patients $(n=14)$ underwent exactly the intended treatment regarding both setting and exact duration (25.0\% of the outpatient group, $31.6 \%$ of the day hospital group and $16.7 \%$ of the inpatient group), and $94.7 \%$ of the patients $(n=54)$ stayed in the assigned setting group (100.0\% of the outpatient group, $94.7 \%$ of the day hospital group and $88.9 \%$ of the inpatient group). Of the 43 patients whose received treatment duration deviated from their intended treatment duration, 17 (39.5\% of the deviating patients) stayed in treatment shorter than planned $(40.0 \%$ of the deviating patients in the outpatient group, $46.2 \%$ in the day hospital group and $33.3 \%$ in the inpatient group). Of these 17 patients, 10 decided in agreement with their therapist that treatment was no longer beneficial or necessary, whereas 7 patients dropped out of treatment prematurely or were forced to leave earlier by the staff. From these 7 dropouts, 1 patient was from the outpatient group $(5.0 \%$ of the total outpatient group), 4 patients were from the day hospital group (21.1\% of the total day hospital group), and 2 patients were from the inpatient group (11.1\% of the total inpatient group). All dropouts were treatment dropouts (and no study dropouts) who completed follow-up measurements and were included in the intention-to-treat analyses.

\section{Treatment Outcome}

Patients in the day hospital and inpatient groups showed larger improvements than patients in the outpatient group (table 3; fig. 3), when inspecting the effect sizes for the 3 different treatment groups without propensity score correction. More specifically, patients of the day hospital and inpatient groups showed significant improvement after 18 months in terms of psychiatric symptoms (GSI), the primary outcome measure $(\mathrm{p}<0.0001)$, whereas patients of the outpatient group did not $(\mathrm{p}=$ $0.16)$. 
Table 2. Baseline characteristics

\begin{tabular}{|c|c|c|c|c|}
\hline Variable & $\begin{array}{l}\text { Outpatient } \\
(\mathrm{n}=20)\end{array}$ & $\begin{array}{l}\text { Day hospital } \\
(\mathrm{n}=19)\end{array}$ & $\begin{array}{l}\text { Inpatient } \\
(\mathrm{n}=18)\end{array}$ & $\begin{array}{l}\text { Total } \\
(\mathrm{n}=57)\end{array}$ \\
\hline \multicolumn{5}{|l|}{ Gender, \% } \\
\hline Male & 40.0 & 10.5 & 38.9 & 29.8 \\
\hline Female & 60.0 & 89.5 & 61.1 & 70.2 \\
\hline Age $^{*}$, years & $33.6 \pm 8.6$ & $28.2 \pm 8.0$ & $25.9 \pm 6.1$ & $29.4 \pm 8.2$ \\
\hline \multicolumn{5}{|l|}{ Education, \% } \\
\hline Low & 55.0 & 57.9 & 16.7 & 43.9 \\
\hline Medium & 10.0 & 10.5 & 11.1 & 10.5 \\
\hline High & 35.0 & 31.6 & 72.2 & 45.6 \\
\hline \multicolumn{5}{|l|}{ Marital status*, \% } \\
\hline Unmarried & 60.0 & 84.2 & 94.4 & 78.9 \\
\hline Married & 20.0 & 15.8 & 5.6 & 14.0 \\
\hline Widowed/divorced & 20.0 & 0.0 & 0.0 & 7.0 \\
\hline \multicolumn{5}{|l|}{ Child care, $\%$} \\
\hline Yes & 30.0 & 10.5 & 5.6 & 15.8 \\
\hline No & 70.0 & 89.5 & 94.4 & 84.2 \\
\hline \multicolumn{5}{|l|}{ Cluster A PD diagnosis, \% } \\
\hline Paranoid PD & 90.0 & 94.7 & 72.2 & 86.0 \\
\hline Schizoid PD & 5.0 & 5.3 & 16.7 & 8.8 \\
\hline Schizotypal PD & 5.0 & 5.3 & 11.1 & 7.0 \\
\hline \multicolumn{5}{|l|}{ PD diagnosis, $\%$} \\
\hline 'Pure' cluster A & 15.0 & 10.5 & 22.2 & 15.8 \\
\hline Cluster A + B & 20.0 & 0.0 & 16.7 & 12.3 \\
\hline Cluster A + C & 40.0 & 31.6 & 22.2 & 31.6 \\
\hline Cluster A, B + C & 25.0 & 57.9 & 38.9 & 40.4 \\
\hline $\mathrm{GSI}^{*}$ & $1.4 \pm 0.7$ & $2.0 \pm 0.6$ & $2.0 \pm 0.8$ & $1.8 \pm 0.8$ \\
\hline OQ-45 Social role & $15.7 \pm 4.7$ & $18.8 \pm 5.4$ & $17.7 \pm 5.5$ & $17.4 \pm 5.3$ \\
\hline OQ-45 Interpersonal relations & $21.4 \pm 5.5$ & $23.7 \pm 6.5$ & $25.5 \pm 4.7$ & $23.5 \pm 5.8$ \\
\hline EQ-5D index* & $0.7 \pm 0.2$ & $0.4 \pm 0.3$ & $0.5 \pm 0.3$ & $0.6 \pm 0.3$ \\
\hline EQ-VAS & $61.9 \pm 18.4$ & $55.4 \pm 19.1$ & $53.2 \pm 16.5$ & $57.0 \pm 18.1$ \\
\hline \multicolumn{5}{|l|}{ Psychotropic medication, $\%$} \\
\hline Yes & 60.0 & 63.2 & 55.6 & 59.6 \\
\hline No & 40.0 & 36.8 & 44.4 & 40.4 \\
\hline
\end{tabular}

Results are expressed as percentages or as means $\pm \mathrm{SD}$, as indicated. ${ }^{*} \mathrm{p} \leq 0.05$ : significant group differences.

Significant improvements for patients from the day hospital and inpatient groups were also observed for social and interpersonal functioning (OQ-45) and for quality of life (EQ-5D index and EQ-VAS). The single outcome measure with significant improvements after 18 months for patients of the outpatient group was OQ-45 social role $(\mathrm{p}=0.02)$. The difference between the outpatient group on the one hand and the day hospital and inpatient groups on the other hand was especially striking for the EQ-VAS score. Patients in the outpatient group started healthier and hardly improved (effect size $=0.04$ ), whereas patients in the day hospital and inpatient groups started treatment less healthy and subsequently improved substantially with effect sizes of 1.03 and 0.74 , respectively.

\section{Group Comparisons of Different Settings}

The group comparisons corrected with the propensity score method confirmed the superiority of day hospital and inpatient treatment in terms of improvement of psychiatric symptoms (GSI), as can be seen in table 4 . After correction for observed pretreatment differences by means of the multiple propensity score, the differences in improvement between outpatient and day hospital treatment and between outpatient and inpatient treatment proved to be significant with $\beta=0.52(\mathrm{p}=0.046)$ and 

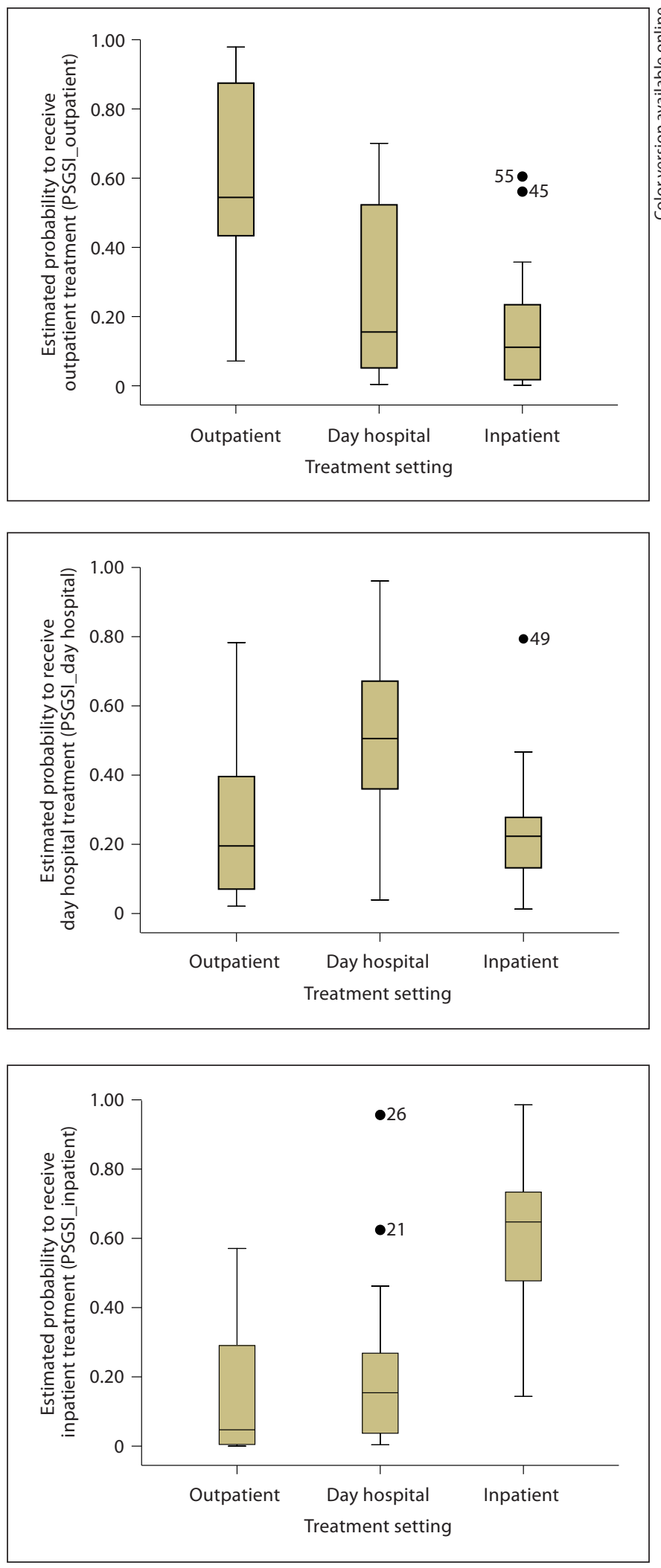

Fig. 2. Overlap in propensity score distributions, outcome GSI. Figures near symbols indicate case numbers of outliers.

Psychotherapy for Cluster A Personality Disorder

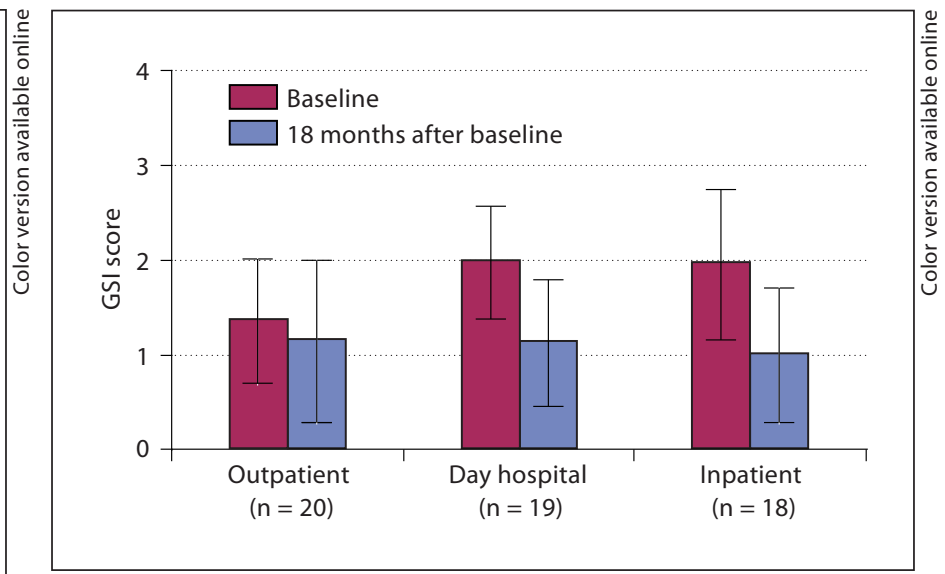

Fig. 3. GSI uncorrected mean scores at baseline and at 18-month follow-up.

$\beta=0.73(p=0.01)$, respectively. The differences in improvement of psychiatric symptoms between day hospital and inpatient treatments were minimal, with $\beta=0.22$ $(\mathrm{p}=0.41)$.

Group differences in the improvement of psychosocial functioning were smaller than the differences in the improvement of psychiatric symptoms, with results that were far from significant. The same holds true for the differences in change scores of the EQ-5D quality of life index. However, the difference in change scores of the EQVAS between outpatient and day hospital treatments was statistically significant $(\beta=23.82 ; p=0.02)$, favouring day hospital treatment.

Taken together, the corrected results suggest most of all a superiority of day hospital and inpatient treatment, as compared to outpatient treatment, with regard to the improvement of psychiatric symptoms 18 months after baseline. However, as mentioned above, these results have to be interpreted cautiously as it appeared from the limited overlap of propensity score distributions that the 3 patient groups consisted of substantially different patients.

\section{Discussion}

\section{Main Findings}

This study examined the effect of psychotherapy on patients with cluster A PD. The most important conclusion is that cluster A personality pathology per se does not seem to be an impediment to benefit from psychotherapeutic treatment.

Psychother Psychosom 2011;80:88-99 
Table 3. Uncorrected outcomes (means $\pm \mathrm{SD}$ ) and effect sizes in 3 treatment groups for all outcome variables

\begin{tabular}{llccc}
\hline Variable & Treatment group & Baseline & 18 months & $\begin{array}{l}\text { Within-group } \\
\text { effect size, } \\
\text { Cohen's d }\end{array}$ \\
\hline GSI & & & & \\
& Outpatient $(\mathrm{n}=20)$ & $1.37 \pm 0.68$ & $1.16 \pm 0.88$ & 0.27 \\
& Day hospital $(\mathrm{n}=19)$ & $1.99 \pm 0.62$ & $1.14 \pm 0.69$ & 1.33 \\
& Inpatient $(\mathrm{n}=18)$ & $1.97 \pm 0.82$ & $1.01 \pm 0.73$ & 1.27 \\
\hline OQ-45 & Outpatient $(\mathrm{n}=20)$ & $15.68 \pm 4.68$ & $11.97 \pm 6.23$ & 0.69 \\
Social role & Day hospital $(\mathrm{n}=19)$ & $18.84 \pm 5.36$ & $13.12 \pm 5.26$ & 1.11 \\
& Inpatient $(\mathrm{n}=18)$ & $17.74 \pm 5.54$ & $11.38 \pm 6.33$ & 1.10 \\
\hline OQ-45 & Outpatient $(\mathrm{n}=20)$ & $21.39 \pm 5.50$ & $18.65 \pm 9.41$ & 0.36 \\
Interpersonal relations & Day hospital $(\mathrm{n}=19)$ & $23.67 \pm 6.50$ & $17.91 \pm 7.40$ & 0.85 \\
& Inpatient $(\mathrm{n}=18)$ & $25.52 \pm 4.74$ & $17.31 \pm 8.12$ & 1.27 \\
\hline EQ-5D index & Outpatient $(\mathrm{n}=20)$ & $0.67 \pm 0.19$ & $0.76 \pm 0.20$ & 0.47 \\
& Day hospital $(\mathrm{n}=19)$ & $0.45 \pm 0.28$ & $0.67 \pm 0.25$ & 0.85 \\
\hline EQ-VAS & Inpatient $(\mathrm{n}=18)$ & $0.53 \pm 0.30$ & $0.69 \pm 0.26$ & 0.59 \\
& Outpatient $(\mathrm{n}=20)$ & $61.90 \pm 18.36$ & $62.55 \pm 17.20$ & 0.04 \\
& Day hospital $(\mathrm{n}=19)$ & $55.42 \pm 19.09$ & $72.06 \pm 13.72$ & 1.03 \\
& Inpatient $(\mathrm{n}=18)$ & $53.17 \pm 16.48$ & $66.13 \pm 19.31$ & 0.74 \\
\hline
\end{tabular}

Table 4. Comparison of change scores from baseline to 18 months after propensity score correction, all outcome variables

\begin{tabular}{llrrr}
\hline Variable & Treatment groups compared & $\beta$ value & 95\% CI & p value \\
\hline GSI & Outpatient $(\mathrm{n}=20)$ vs. day hospital $(\mathrm{n}=19)$ & 0.52 & 0.01 to 1.03 & 0.046 \\
& Outpatient $(\mathrm{n}=20)$ vs. inpatient $(\mathrm{n}=18)$ & 0.73 & 0.16 to 1.30 & 0.01 \\
& Day hospital $(\mathrm{n}=19)$ vs. inpatient $(\mathrm{n}=18)$ & 0.22 & -0.31 to 0.74 & 0.41 \\
\hline OQ-45 & Outpatient $(\mathrm{n}=20)$ vs. day hospital $(\mathrm{n}=19)$ & -0.58 & -4.89 to 3.73 & 0.79 \\
Social role & Outpatient $(\mathrm{n}=20)$ vs. inpatient $(\mathrm{n}=18)$ & 0.97 & -3.24 to 5.18 & 0.65 \\
& Day hospital $(\mathrm{n}=19)$ vs. inpatient $(\mathrm{n}=18)$ & 1.55 & -2.42 to 5.53 & 0.44 \\
\hline OQ-45 & Outpatient $(\mathrm{n}=20)$ vs. day hospital $(\mathrm{n}=19)$ & 0.68 & -4.41 to 5.76 & 0.79 \\
Interpersonal & Outpatient $(\mathrm{n}=20)$ vs. inpatient $(\mathrm{n}=18)$ & 2.87 & -2.27 to 8.02 & 0.27 \\
relations & Day hospital $(\mathrm{n}=19)$ vs. inpatient $(\mathrm{n}=18)$ & 2.20 & -2.50 to 6.89 & 0.35 \\
\hline EQ-5D index & Outpatient $(\mathrm{n}=20)$ vs. day hospital $(\mathrm{n}=19)$ & 0.01 & -0.12 to 0.15 & 0.83 \\
& Outpatient $(\mathrm{n}=20)$ vs. inpatient $(\mathrm{n}=18)$ & 0.03 & -0.11 to 0.16 & 0.68 \\
& Day hospital $(\mathrm{n}=19)$ vs. inpatient $(\mathrm{n}=18)$ & 0.01 & -0.11 to 0.14 & 0.83 \\
\hline EQ-VAS & Outpatient $(\mathrm{n}=20)$ vs. day hospital $(\mathrm{n}=19)$ & 23.82 & 3.92 to 43.72 & 0.02 \\
& Outpatient $(\mathrm{n}=20)$ vs. inpatient $(\mathrm{n}=18)$ & -0.20 & -36.39 to 36.00 & 0.99 \\
& Day hospital $(\mathrm{n}=19)$ vs. inpatient $(\mathrm{n}=18)$ & -24.01 & -61.88 to 13.85 & 0.21 \\
\hline
\end{tabular}

$\beta$ values: positive coefficients indicate that the last treatment group shown is superior, negative coefficients indicate that the first treatment group is superior. CI = Confidence interval. 
The majority of the study sample presented with a diagnosis of paranoid PD and showed high comorbidity with the 2 other PD clusters. When comparing the 3 treatment groups, it appeared that - with regard to psychiatric symptoms - patients in the day hospital and inpatient groups improved more than patients in the outpatient group.

\section{Strengths and Limitations}

Strengths of the present study are its considerable sample size for a cluster A PD population and its naturalistic design, which made it possible to gain insight into treatments as given in daily clinical practice. Furthermore, the attempt of powerful statistical control of potential confounders, using the multiple propensity score methodology, is unique in the cluster A literature.

Nevertheless, this study also had limitations. First, due to substantial baseline differences of patients in the 3 treatment groups, a direct comparison of the 3 settings was difficult to conduct. Higher treatment gains cannot readily be attributed to a certain treatment, as variables other than treatment group might have played a role. That outpatients improve less may be due to the fact that they are older at the start of treatment or have a heavier burden of care responsibilities at home. The present study cannot rule out that patient characteristics played a role in the explanation of the results, as overlap of propensity score distributions was limited. Second, even though we controlled for all observed pretreatment differences, it cannot be ruled out that results were influenced by other, unobserved confounders. To minimise this last risk as much as possible, a broad range of possible confounders was carefully selected and measured, based on both clinical and empirical knowledge [58]. If related to outcome, these variables were included in the propensity score. Third, the majority of patients had a diagnosis of paranoid PD which makes its results mainly applicable to this diagnostic group and to a lesser extent to patients with schizotypal and schizoid PD. Fourth, the high comorbidity with other PD clusters makes it questionable to attribute the treatment gains to an improvement in cluster A pathology. Possibly the improvement observed in our study is due to advances made in a different area of psychiatric impairment. Nevertheless, the main conclusion stays valid: improvement in different areas of life is possible for patients with cluster A PD who undergo psychotherapeutic treatment.

\section{Clinical Significance}

The differences in improvement between outpatients on the one hand and day hospital and inpatients on the other hand are striking, especially compared to the poor results of day hospital treatment in cluster A PD patients found by Karterud et al. [38]. These authors found an effect size of 0.23 (versus 1.33 in the present study), when measuring change in GSI scores of paranoid and schizotypal patients from baseline to follow-up (1 year after discharge with a mean treatment duration of \pm 5 months, i.e. comparable to our 18 months after baseline). Might day hospital and inpatient treatment nevertheless be the preferable treatment options for this patient group? The present data suggest this conclusion, especially because these patients start off worse compared to outpatients and seem to improve more during treatment. Moreover, this effect cannot be explained by the influence of dropout rates, as treatment compliance was even lower in the day hospital (21.1\% dropout rate) and inpatient group (11.1\% dropout rate) compared to the outpatient group (5.0\% dropout rate). The day hospital dropout rate is comparable to the one of Karterud et al. [38] (23.9\%). One possible explanation for the differences between the two studies might be that our treatment duration was twice as long as the one of Karterud et al. Maybe cluster A patients need a longer treatment duration to experience change. A complication is that regression to the mean might also explain a part of the observed effect, as the patients with the highest baseline severity showed the highest improvement. For ethical reasons we were not able to compare our findings to a control group receiving no treatment at all. Clearly, more research is needed to further elucidate these findings before drawing major conclusions. The only conclusion we can draw from our findings with confidence is that cluster A pathology does not seem to be a contraindication for psychotherapy.

\section{Implications for Research and Public Health}

What are the implications of the present results for future research, clinical practice and public health policy?

We found that cluster A pathology does not seem to form an impediment for psychotherapeutic treatment and that gains in different areas of life can be observed in patients with cluster A PD. Bearing the limitations of this pioneering study in mind, this might be the first step towards a revised vision of this patient group in mental health practice. Some 20 years ago, patients with borderline PD were considered as 'untreatable', whereas now a multitude of treatment protocols have been developed for this patient group and research on their implementation showed encouraging results [60-62]. The same could be true for cluster A PD patients. An important question for further treatment research for this patient population is: 
are more intensive treatments such as day hospital and inpatient treatment indeed the treatment of choice for cluster A PD patients as our results seem to suggest, and, if yes, how can they be tailored to this population?

Now that we presume that cluster A pathology does not necessarily interfere with psychotherapeutic treatment, cluster A PD patients should not a priori be excluded from psychotherapy. On the contrary, if our results can be replicated, it would be important to make psychotherapy more accessible for this patient group in order to reach health gains for this vulnerable group of psychiatric patients. Concluding, clinical practice may be more optimistic regarding psychotherapeutic treatment in cluster A PD patients.

\section{Acknowledgements}

We are very grateful to Els Havermans who helped with the data collection. We also thank all the patients and therapists who took part in the study.

\section{Disclosure Statement}

The authors report no financial or other relationship relevant to the subject of this article.

\section{References}

1 Bornstein RF, Klein DN, Mallon JC, Slater JF: Schizotypal personality disorder in an outpatient population: incidence and clinical characteristics. J Clin Psychol 1988;44: 322-325.

-2 Reich JH, Green AI: Effect of personality disorders on outcome of treatment. J Nerv Ment Dis 1991;179:74-82.

- 3 Bender DS, Dolan RT, Skodol AE, Sanislow CA, Dyck IR, McGlashan TH, Shea MT, Zanarini MC, Oldham JM, Gunderson JG: Treatment utilization by patients with personality disorders. Am J Psychiatry 2001; 158:295-302.

-4 Seivewright $\mathrm{H}$, Tyrer P, Johnson T: Change in personality status in neurotic disorders. Lancet 2002;359:2253-2254.

5 Skodol AE, Gunderson JG, Shea MT, McGlashan TH, Morey LC, Sanislow CA, Bender DS, Grilo CM, Zanarini MC, Yen S, Pagano ME, Stout RL: The Collaborative Longitudinal Personality Disorders Study (CLPS): overview and implications. J Pers Disord 2005; 19:487-504.

-6 McGlashan TH, Grilo CM, Sanislow CA, Ralevski E, Morey LC, Gunderson JG, Skodol AE, Shea MT, Zanarini MC, Bender D, Stout RL, Yen S, Pagano M: Two-year prevalence and stability of individual DSM-IV criteria for schizotypal, borderline, avoidant, and obsessive-compulsive personality disorders: toward a hybrid model of axis II disorders. Am J Psychiatry 2005;162:883-889.

$\checkmark 7$ Coid J, Yang M, Tyrer P, Roberts A, Ullrich $S$ : Prevalence and correlates of personality disorder in Great Britain. Br J Psychiatry 2006; 188:423-431.

${ }_{8}$ Samuels J, Eaton WW, Bienvenu OJ III, Brown $\mathrm{CH}$, Costa PT Jr, Nestadt G: Prevalence and correlates of personality disorders in a community sample. Br J Psychiatry 2002; 180:536-542.
$\$ 9$ Torgersen S, Kringlen E, Cramer V: The prevalence of personality disorders in a community sample. Arch Gen Psychiatry 2001; 58:590-596.

10 Zimmerman M, Rothschild L, Chelminski I: The prevalence of DSM-IV personality disorders in psychiatric outpatients. Am J Psychiatry 2005; 162:1911-1918.

11 Bartak A, Soeteman DI, Verheul R, Busschbach JJV: Strengthening the status of psychotherapy for personality disorders: an integrated perspective on effects and costs. Can J Psychiatry 2007;52:803-810.

12 Stone MH: Schizotypal personality: psychotherapeutic aspects. Schizophr Bull 1985;11: 576-589.

13 The Quality Assurance Project: Treatment outlines for paranoid, schizotypal and schizoid personality disorders. Aust NZ J Psychiatry 1990;24:339-350.

14 Gabbard GO: Psychotherapy of personality disorders. J Psychother Pract Res 2000;9:16.

15 Jenike MA, Baer L, Minichiello WE, Schwartz CE, Carey RJ Jr: Concomitant obsessive-compulsive disorder and schizotypal personality disorder. Am J Psychiatry 1986; 143:530-532.

16 Minichiello WE, Baer L, Jenike MA: Schizotypal personality disorder: a poor prognostic indicator for behavior therapy in the treatment of obsessive-compulsive disorder. J Anxiety Disord 1987;1:273-276.

17 Baer L, Jenike MA, Black DW, Treece C, Rosenfeld R, Greist J: Effect of axis II diagnoses on treatment outcome with clomipramine in 55 patients with obsessive-compulsive disorder. Arch Gen Psychiatry 1992; 49:862-866.
18 Sato T, Sakado K, Sato S, Morikawa T: Cluster A personality disorder: a marker of worse treatment outcome of major depression? Psychiatry Res 1994;53:153-159.

19 Mulder RT, Joyce PR, Frampton CM, Luty SE, Sullivan PF: Six months of treatment for depression: outcome and predictors of the course of illness. Am J Psychiatry 2006;163: 95-100.

20 Serban G, Siegel S: Response of borderline and schizotypal patients to small doses of thiothixene and haloperidol. Am J Psychiatry 1984;141:1455-1458.

21 Hymowitz P, Frances A, Jacobsberg LB, Sickles M, Hoyt R: Neuroleptic treatment of schizotypal personality disorders. Compr Psychiatry 1986;27:267-271.

22 Goldberg SC, Schulz SC, Schulz PM, Resnick RJ, Hamer RM, Friedel RO: Borderline and schizotypal personality disorders treated with low-dose thiothixene vs placebo. Arch Gen Psychiatry 1986;43:680-686.

23 Markovitz PJ, Calabrese JR, Schulz SC, Meltzer HY: Fluoxetine in the treatment of borderline and schizotypal personality disorders. Am J Psychiatry 1991;148:1064-1067.

24 Koenigsberg HW, Reynolds D, Goodman M, New AS, Mitropoulou V, Trestman RL, Silverman J, Siever LJ: Risperidone in the treatment of schizotypal personality disorder. J Clin Psychiatry 2003;64:628-634.

25 Keshavan M, Shad M, Soloff P, Schooler N: Efficacy and tolerability of olanzapine in the treatment of schizotypal personality disorder. Schizophr Res 2004;71:97-101.

26 Kapfhammer H-P, Hippius H: Special feature: pharmacotherapy in personality disorders. J Pers Disord 1998;12:277-288. 
-27 Herpertz SC, Zanarini M, Schulz CS, Siever L, Lieb K, Möller H-J: World Federation of Societies of Biological Psychiatry (WFSBP) guidelines for biological treatment of personality disorders. Wrld J Biol Psychiatry 2007;8:212-244.

-28 Duggan C, Huband N, Smailagic N, Ferriter M, Adams CE: The use of pharmacological treatments for people with personality disorder: a systematic review of randomized controlled trials. Pers Mental Health 2008;2: 119-170.

-29 Ingenhoven T, Lafay P, Rinne T, Passchier J, Duivenvoorden $\mathrm{H}$ : Effectiveness of pharmacotherapy for severe personality disorders: meta-analyses of randomized controlled trials. J Clin Psychiatry 2010;71:14-25.

30 Coccaro EF: Clinical outcome of psychopharmacologic treatment of borderline and schizotypal personality disordered subjects. J Clin Psychiatry 1998;59:30-35.

- 31 Stone MH: Long-term outcome in personality disorders. Br J Psychiatry 1993;162:299313.

- 32 Plakun EM, Burkhardt PE, Muller JP: 14year follow-up of borderline and schizotypal personality disorders. Compr Psychiatry 1985;26:448-455.

-33 Endicott J, Spitzer RL, Fleiss JL, Cohen J: The Global Assessment Scale: a procedure for measuring overall severity of psychiatric disturbance. Arch Gen Psychiatry 1976;33:766771.

- 34 Mehlum L, Friis S, Irion T, Johns S, Karterud S, Vaglum P, Vaglum S: Personality disorders 2-5 years after treatment: a prospective follow-up study. Acta Psychiatr Scand 1991;84: 72-77.

- 35 Karterud S, Vaglum S, Friis S, Irion T, Johns S, Vaglum P: Day hospital therapeutic community treatment for patients with personality disorders: an empirical evaluation of the containment function. J Nerv Ment Dis 1992;180:238-243.

- 36 Winston A, Laikin M, Pollack J, Samstag LW, McCullough L, Muran JC: Short-term psychotherapy of personality disorders. Am J Psychiatry 1994;151:190-194.

-37 Gude T, Vaglum P: One-year follow-up of patients with cluster $\mathrm{C}$ personality disorders: a prospective study comparing patients with 'pure' and comorbid conditions within cluster $\mathrm{C}$, and 'pure' $\mathrm{C}$ with 'pure' cluster $\mathrm{A}$ or $\mathrm{B}$ conditions. J Pers Disord 2001;15:216-228.

- 38 Karterud S, Pedersen G, Bjordal E, Brabrand J, Friis S, Haaseth $\varnothing$, Haavaldsen G, Irion T, Leirvåg H, Tørum E, Urnes Ø: Day treatment of patients with personality disorders: experiences from a Norwegian treatment research network. J Pers Disord 2003;17:243262.
39 Bartak A, Spreeuwenberg MD, Andrea H, Holleman L, Rijnierse P, Rossum BV, Hamers EFM, Meerman AMMA, Aerts J, Busschbach JJV, Verheul R, Stijnen T, Emmelkamp PMG: Effectiveness of different modalities of psychotherapeutic treatment for patients with cluster $\mathrm{C}$ personality disorders: results of a large prospective multicentre study. Psychother Psychosom 2010;79:20-30.

40 Bartak A, Andrea H, Spreeuwenberg MD, Ziegler UM, Dekker J, Rossum BV, Hamers EFM, Scholte W, Aerts J, Busschbach JJV, Verheul R, Stijnen T, Emmelkamp PMG: Effectiveness of outpatient, day hospital, and inpatient psychotherapeutic treatment for patients with cluster B personality disorders. Psychother Psychosom 2011;80:28-38.

41 Vervaeke GAC, Emmelkamp PMG: Treatment selection: what do we know? Eur J Psychol Assess 1998:14:50-59.

42 Van Manen J, Kamphuis JH, Visbach G, Ziegler UM, Gerritsen A, van Rossum B, Rijnierse P, Timman R, Verheul R: How do intake clinicians use patient characteristics to select treatment for patients with personality disorders? Psychother Res 2008;18:711718.

43 De Jong CAJ, Derks FCH, van Oel CJ, Rinne T: Gestructureerd interview voor de DSMIV persoonlijkheidsstoornissen (SIDP-IV). Sint Oedenrode, Stichting Verslavingszorg Oost Brabant, 1996.

44 Pfohl B, Blum N, Zimmerman M: Structured Interview for DSM-IV Personality (SIDPIV). Washington, American Psychiatric Press, 1997.

45 Livesley WJ, Jackson DN: Manual for the Dimensional Assessment of Personality $\mathrm{Pa}$ thology - Basic Questionnaire (DAPP-BQ) Port Huron, Sigma Press, 2002

46 Van Kampen D: The DAPP-BQ in the Netherlands: factor structure and relationship with basic personality dimensions. J Pers Disord 2002;16:235-254.

47 Verheul R, Andrea H, Berghout CC, Dolan C, Busschbach JJV, van der Kroft PJA, Bateman AW, Fonagy P: Severity Indices of Personality Problems (SIPP-118): development, factor structure, reliability, and validity. Psychol Assess 2008;20:23-34.

48 Van Beek N, Verheul R: Motivation for treatment in patients with personality disorders. J Pers Disord 2008;22:89-100.

49 Derogatis LR, Melisaratos N: The Brief Symptom Inventory: an introductory report. Psychol Med 1983;13:595-605.

50 De Beurs E, Zitman FG: De Brief Symptom Inventory (BSI): de betrouwbaarheid en validiteit van een handzaam alternatief voor de SCL-90. Maandblad Geestelijke Volksgezondheid 2006;61:120-141.
51 Derogatis LR: SCL-90-R: Administration, Scoring and Procedure. Manual II for the Revised Version. Townson, Clinical Psychometric Research, 1986.

52 Arrindell WA, Ettema JHM: SCL-90-R: Herziene handleiding bij een multidimensionele psychopathologie-indicator. Lisse, Swets \& Zeitlinger, 2003.

53 Lambert MJ, Burlingame GM, Umphress V, Hansen NB, Vermeersch DA, Clouse GC, Yanchar SC: The reliability and validity of the outcome questionnaire. Clin Psychol Psychother 1996;3:249-258.

54 Brooks R, Rabin R, de Charro F (eds): The Measurement and Valuation of Health Status Using EQ-5D: A European Perspective. Dordrecht, Kluwer Academic Publishers, 2003.

55 Cohen J: Statistical power analysis for the behavioral sciences, ed 2. Hillsdale, Lawrence Erlbaum Associates, 1988.

56 Rosenbaum PR, Rubin DB: The central role of the propensity score in observational studies for causal effects. Biometrika 1983; 70:41-55.

57 Imbens GW: The role of the propensity score in estimating dose-response functions. Biometrika 2000;87:706-710.

58 Bartak A, Spreeuwenberg MD, Andrea H, Busschbach JJV, Croon MA, Verheul R, Emmelkamp PMG, Stijnen T: The use of propensity score methods in psychotherapy research: a practical application. Psychother Psychosom 2009;78:26-34.

59 Spreeuwenberg MD, Bartak A, Croon MA, Hagenaars JA, Busschbach JJV, Andrea H, Twisk J, Stijnen T: The multiple propensity score as control for bias in the comparison of more than two treatment arms: an introduction from a case study in mental health. Med Care 2010;48:166-174.

60 Bateman AW, Fonagy P: Treatment of borderline personality disorder with psychoanalytically oriented partial hospitalization: an 18-month follow-up. Am J Psychiatry 2001;158:36-42.

61 Giesen-Bloo J, van Dyck R, Spinhoven P, van Tilburg W, Dirksen C, van Asselt T, Kremers I, Nadort M, Arntz A: Outpatient psychotherapy for borderline personality disorder: randomized trial of schema-focused therapy vs transference-focused psychotherapy. Arch Gen Psychiatry 2006;63:649-658.

62 Clarkin JF, Levy KN, Lenzenweger MF, Kernberg OF: Evaluating three treatments for borderline personality disorder: a multiwave study. Am J Psychiatry 2007;164:922928 